\title{
DO PRAZER E DO DIVERTIMENTO - ESTUDO SOBRE BARTHES E PALAZZESCHI
}

\author{
Aurora $F \quad$ Bernardini
}

O prazer de Barthes é, eminentemente (Cf. Le plaisir du texte (1), o prazer de quem lê o texto, de quem descobre quintessências de uma fruição onde "os dados não estejam lançados", onde haja intertexto, esta "impossibilidade de viver fora do texto infinito"

A fruição a que o autor se refere e que visa o texto literário em geral, tem diante de si um campo de aplicação extremamente vasto e, como conseqüência, prevê uma serie quase infinita de aspectos, de "coagulações de significâncias", em sua terminologia. Um desses aspectos, um tipo particular de fruição, portanto, intervém de maneira singular quando o texto é libertado (pelo leitor) dos imaginários da linguagem (a palavra como unidade singular, mônada mágica; a fala como instrumento ou expressão do pensamento; a escrita como transliteração da fala; a frase como medida lógica, fechada; a própria carência ou recusa de linguagem como força primária, espontânea, pragmática) (2)

Ora, quando esta libertação é praticada pelo autor (quase sempre o é pelo poeta - de modo mais ou menos intencional, mais ou menos consciente) até tornar-se procedimento maciço, reiterado, transforma o texto em linguagem zaum, que vai desde o enigmático cifrado (Khlébnikov, Joyce, Krutchônikh, Jorge de Sena. ) até o "divertimento" dos futuristas italianos.

No "divertimento" o prazer obtível é um prazer menor: justamente, como não queria Barthes (3), um elemento previsto pelo texto, um resíduo mais ou menos ingênuo, comum, em dosagens diferentes, ao autor e ao leitor

Particularmente em Palazzeschi, o "divertimento" é levado, diríamos, ao pé da letra. As conseqüências que disso decorrem são bas-

(1) - Barthes R. - Le Plaisir du texte, Paris, Seuil, 1973.

(2) - Barthes R. - O prazer do texto, Lisboa, Edições 70, 1974, p. 73.

(3) - Idem, ibidem, p. 61. 
tante curiosas: por um lado põem-se como um discurso sobre a própria técnica e (o paradoxo é apenas aparente) como uma técnica do próprio discurso; - por outro lado - de um ponto de vista mais diacrônico, o paradoxo se atualiza como rovesciamento dos 'imaginários do texto' e de certos conceitos quais a piedade, o afeto e, mais do que todos, o prazer Prova da eficácia de tal atitude é seu manif́esto "Il Controdolore" (o melhor dos escritos por ele, se considerarmos a opinião de seus críticos mais ilustres: Sanguineti, por exemplo); nós, porém, preferimos considerar seu poema "Lasciatemi divertire" (unia canzonetta - como ele quis chamá-la), que por sua natureza dupla e por seu caráter, de certa forma transmental e metalingüístico, tem um alcance mais vasto e mais original.

Lasciatemi divertire

$$
\text { canzonetta }
$$

Tri tri tri, fru fru fru, uhi uhi uhi, ihu ihu ihu.

Il poeta si diverte, pazzamente, smisuratamente.

Non lo estate a insolentire, lasciatelo divertire poveretto, queste piccole corbellerie sono il suo diletto.

Cucú rurú, rurú cucú, cuccuccurucú!

Cosa sono queste indecenze?

Queste strofe bisbetiche?

Licenze, licenze, licenze poetiche.

Sono la mia passione.

Farafarafarafa, Tarataratarata, Paraparaparapa, Laralaralarala!

Sapete cosa sono?

Sono robe avanzete, 
non sono grullerie,

sono la. spazzatura

delle altre poesie.

Bubububu,

fufufufu,

Friú!

Friú!

Se d'un qualunque nesso

son prive,

perché le scrive

quel fesso?

Bilobilobilobilobilo

blum!

Filofilofilofilofilo

flum!

Bilolú. Filolú.

U.

Non è vero che non voglion dire, vogliono dire qualcosa.

Voglion dire...

come quando uno si mette a cantare

senza saper le parole.

Una cosa molto volgare.

Ebbene, cosí mi piace di fare.

Aaaaa!

Eeee!

Iiiii!

Ooooo!

Uuuuu!

A! E! I! O! U!

Ma giovinotto,

diteci un poco una cosa,

non è la vostra una posa,

di voler con cosí poco

tenere alimentato

un sí gran foco?

Huisc. . Huiusc...

Huisciu. . sciu sciu,

Sciukoku... koku koku, 
Sciu

ko

ku

Come si deve fare a capire?

Avete delle belle pretese, sembra ormai che scriviate in giapponese.

Abí, Alí, alarí.

Riririri!

Ri.

Lasciate pure che si sbizzarrisca, anzi, è bene che non lo finisca, il divertimento gli costerà caro: gli claranno del somaro.

Lalala

falala

falala.

eppoi lala.

e lalala, lalalalala lalala.

Certo è un azzardo un po'forte scrivere delle cose cosí, che ci son professori, oggidi, a tutte le porte.

Ahahahahahahah!

Ahahahahahahah!

Ahahahahahahah!

Infine,

io ho pienamente ragione,

i tempi sono cambiati,

gli uomini non domandano piú nulla

dai poeti:

e lasciatemi divertíre!

Fundamentalmente, como explicita o poeta na estrofe X, o poema tssemelha-se ao esqueleto sonoro de uma canção: "come quando uno si mette a cantare senza saper le parole" Tal 'esqueleto' é uma ocorrência comum na gênese poética - mas, neste exemplo encontram-se estilizados, sonora e graficamente, alguns de seus procedimentos técnicos mais curiosos. A estrofe XI, por exemplo, em sua primariedade: 
Aaaaa!

Eeeee!

Iiiii!

Ooooo!

Uuuuu!

A! E! I! O! U!

transmite 'telegraficamente' as noções de expansão, síntese, rélevo, contraste. Já a repetição, a anáfora, a palíndrome, a condensação, a dissociação, o eco, a reticência, são particularmente visíveis nas estrofes I, III, XIII e IX.

Em alguns momentos temos a impressão de que se trata de um mero exercício de som (estrofe V), mas na verdade, justamente os versos menos desprovidos de um nexo lógico aparente, são os istruturalmente mais significativos. Funcionam eles como resposta-caricatura às estrofes que questionam. Exemplificamos, para maior clareza:

Come si deve fare a capire?

Avete delle belle pretese,

sembra ormai che scriviate in giapponese,

e, eis a 'resposta':
Abi, ali, alari.
Riririri!
Ri.

ou então:

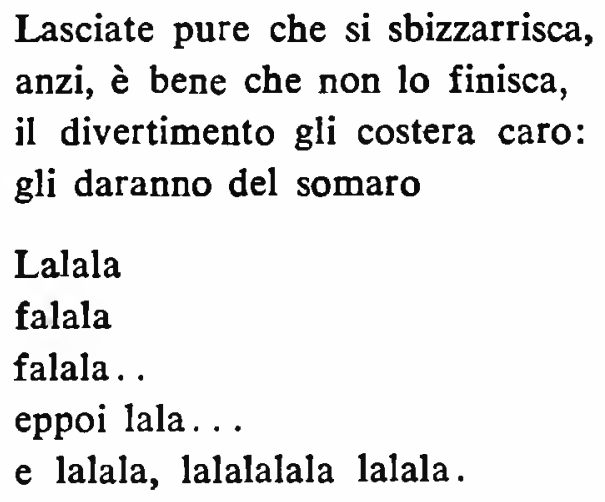

Assim, todas as estrofes ímpares parecem responder às pares ou seja, para usar uma expressão bastante oportuna da língua jtaliana 'sono versi che fanno il verso ad altri versi'; é a linguagem poética que se defende com suas próprias armas.

Se considerarmos porém, sob outra luz, as estrofes pares (particularmente a última): 
Infine,

io ho pienamente ragione,

i tempi sono cambiati,

gli uomini non domandano piu nulla

dai poeti:

e lasciatemi divertire!)

observaremos que elas remetem a uma reflexão conteudística de ordem das mais controversas e das sempre atuais: para que serve a poesia?

A resposta a essa pergunta, na obra de Palazzeschi, encontra-se no Riso. Não se trata porém, de um riso qualquer: o homem ri do próprio riso 'dopo aver fatto un lavoro di scavo nel dolore umano' Desta forma lhe é possível combater a dor fisica e moral com sua própria paródia. A técnica que propõe, exposta detalhadamente em "Il Controdolore", é a da antecipação e do 'aprofundamento' de quanto é humanamente triste:

"Bisogna abituarsi a ridere di tutto quello di cui attualmente si piange... Quello che si dice il dolore umano non e che il corpo caldo e intenso della gioia ricoperto di una gelatina di fredde lacrime grigiastre.

Scortecciate e troverete la felicità. (4)"

(4) - Citações retiradas do manifesto "Il Controdolore" In: - La cultura italiana del '900 attraverso le riviste, Torino, Einaudi, 1963, vol. IV p. 244. (aos cuidados de Gianni Scalia). 